\title{
Mechanical Stress Activates Protein Kinase Cascade of Phosphorylation in Neonatal Rat Cardiac Myocytes
}

Tsutomu Yamazaki, Issei Komuro, Sumiyo Kudoh, Yunzeng Zou, Ichiro Shiojima, Takehiko Mizuno, Hiroyuki Takano, Yukio Hiroi, Kohjiro Ueki, Kazuyuki Tobe, Takashi Kadowaki, Ryozo Nagai, and Yoshio Yazaki

Third Department of Medicine, University of Tokyo School of Medicine, Tokyo 113, Japan

\begin{abstract}
We have previously shown that stretching cardiac myocytes evokes activation of protein kinase $\mathrm{C}$ (PKC), mitogen-activated protein kinases (MAPKs), and 90-kD ribosomal S6 kinase $\left(\mathrm{p}^{\mathrm{9}}{ }^{\mathrm{rsk}}\right)$. To clarify the signal transduction pathways from external mechanical stress to nuclear gene expression in stretch-induced cardiac hypertrophy, we have elucidated protein kinase cascade of phosphorylation by examining the time course of activation of MAP kinase kinase kinases (MAPKKKs), MAP kinase kinase (MAPKK), MAPKs, and p90 ${ }^{\text {rsk }}$ in neonatal rat cardiac myocytes. Mechanical stretch transiently increased the activity of MAPKKKs. An increase in MAPKKKs activity was first detected at $1 \mathrm{~min}$ and maximal activation was observed at 2 min after stretch. The activity of MAPKK was increased by stretch from 1-2 min, with a peak at 5 min after stretch. In addition, MAPKs and p90 ${ }^{\text {rsk }}$ were maximally activated at 8 min and at $10 \sim 30$ min after stretch, respectively. Raf-1 kinase (Raf-1) and (MAPK/extracellular signal-regulated kinase) kinase kinase (MEKK), both of which have MAPKKK activity, were also activated by stretching cardiac myocytes for $2 \mathrm{~min}$. The angiotensin II receptor antagonist partially suppressed activation of Raf-1 and MAPKs by stretch. The stretchinduced hypertrophic responses such as activation of Raf-1 and MAPKs and an increase in amino acid uptake was partially dependent on PKC, while a PKC inhibitor completely abolished MAPK activation by angiotensin II. These results suggest that mechanical stress activates the protein kinase cascade of phosphorylation in cardiac myocytes in the order of Raf-1 and MEKK, MAPKK, MAPKs and p90 ${ }^{\text {rsk }}$, and that angiotensin II, which may be secreted from stretched myocytes, may be partly involved in stretch-induced hypertrophic responses by activating PKC. (J. Clin. Invest. 1995. 96:438-446.) Key words: cardiac hypertrophy - signal transduction - Raf-1 kinase - mitogen-activated protein kinase kinase $\cdot$ mitogen-activated protein kinase
\end{abstract}

\section{Introduction}

Cardiac hypertrophy is an important cause of increased morbidity and mortality (1). The hypertrophied heart exhibits impaired

Address correspondence to Issei Komuro, Third Department of Medicine, University of Tokyo School of Medicine, 7-3-1 Hongo, Bunkyoku, Tokyo 113, Japan. Phone: 81-3-3815-5411 ext. 3127; FAX: 81-33815-2087.

Received for publication 3 November 1994 and accepted in revised form 22 March 1995.

J. Clin. Invest.

(C) The American Society for Clinical Investigation, Inc. 0021-9738/95/07/0438/09\$2.00

Volume 96, July 1995, 438-446 contraction and relaxation, and reduced coronary reserve after transient ischemia, both of which lead to higher mortality in heart failure and ischemic heart disease. Many lines of evidence have suggested that mechanical stress plays a key role in producing cardiac hypertrophy during hemodynamic overload (for a review, see reference 2). Both in vivo and in vitro studies have demonstrated that myocyte hypertrophy induced by pressure overload is characterized by the expression of some immediate early genes as an early event and of fetal type genes as a late event, as well as by an increase in protein synthesis (2-6). While the outcome of hypertrophy has been extensively characterized, little is known concerning the signaling pathways that link the external mechanical stress and the cellular and nuclear events during hypertrophy. Effective prevention and regression of cardiac hypertrophy require a better understanding of the molecular mechanisms of cardiac hypertrophy.

External stimuli are generally transduced into the nucleus through the protein kinase cascade of phosphorylation. It has been reported that protein kinase $\mathrm{C}$ (PKC) ${ }^{1}$ is activated by stretching cardiac myocytes (5). Our recent studies have demonstrated that mitogen-activated protein kinases (MAPKs) are activated by mechanical stress during cardiac myocyte hypertrophy through both PKC-dependent and independent pathways (7). The upstream activator of MAPKs is reported to be MAP kinase kinase (MAPKK) (8-10), which is a dual-specificity protein kinase that phosphorylates MAPKs on both threonine and tyrosine residues within a conserved threonine-glutamic acid-tyrosine motif (11). MAPKK is also activated by phosphorylation of two serine residues (12). Current candidates for this role in mammalian cells are the protooncogene protein kinase Raf-1 kinase (Raf-1) (13) and (MAPK/extracellular signal-regulated kinase) kinase kinase (MEKK) (14). Raf-1 has been reported in many cell types to be activated through PKC-dependent and independent pathways (15), and MEKK has been suggested to mediate primary signals originating from receptors that activate $G$ proteins and PKC (14). Activated MAPKs translocate into the nucleus and activate nuclear transcription factors such as c-myc, NF-IL6, and Elk-1 (for a review, see reference 16). Moreover, 90-kD ribosomal S6 kinase $\left(\mathrm{p} 90^{\text {rsk }}\right)$ is reported to be a downstream enzyme of MAPKs (17) and to phosphorylate nuclear lamins (18). These observations

\footnotetext{
1. Abbreviations used in this paper: Ang II, angiotensin II; MAPK, mitogen-activated protein kinase; MAPKK, MAP kinase kinase; MAPKKK, MAP kinase kinase kinase; MBP, myelin basic protein; MEKK, (MAPK/extracellular signal-regulated kinase) kinase kinase; p90 ${ }^{\text {rsk }}, 90-\mathrm{kD}$ ribosomal S6 kinase; PKC, protein kinase C; Raf-1, Raf1 kinase; $\alpha$-raf, anti-Raf-1 kinase antibodies; rMAPK, recombinant MAPK fused to maltose binding protein; rMAPKK, recombinant MAPKK fused to glutathione $\mathrm{S}$ transferase; TPA, 12-O-tetradecanoylphorbol-13-acetate.
} 
suggest that MAPKs and $\mathrm{p} 90^{\text {rsk }}$ play vital roles in transducing signals into the nucleus.

The aim of this study is to elucidate the signal transduction pathways in cardiac hypertrophy evoked by mechanical stress. For this purpose, we examined the activation of protein kinases such as Raf-1, MEKK, MAPKK, MAPKs, and p90 ${ }^{\text {rsk }}$ after stretching myocytes. Mechanical stress induces sequential phosphorylation and activation of these protein kinases in the order of Raf-1, MEKK, MAPKK, MAPKs, and $\mathrm{p} 90^{\text {rsk }}$. A growing body of data suggests that all components of renin-angiotensin system exist in the heart and that angiotensin II (Ang II) can induce cardiac hypertrophy (19). Moreover, recent reports suggest that Ang II is involved in mechanical stress-induced cardiac hypertrophy (20-22). In the present study, we then present the data suggesting that activation of the protein kinases by stretching myocytes is induced both through Ang II-dependent and independent pathways. While the activation of protein kinases by mechanical stress is partially dependent on PKC, Ang II, which may be secreted by stretched myocytes into the culture media, induces activation of protein kinases in a mostly PKCdependent manner.

\section{Methods}

$\left[\gamma-{ }^{32} \mathrm{P}\right] \mathrm{ATP}$ and $\left[{ }^{3} \mathrm{H}\right]$ phenylalanine were purchased from Du Pont-New England Nuclear Co. (Boston, MA); DMEM and fetal bovine serum (FBS) from GIBCO BRL Co. (Gaithersburg, MD); polyclonal antibody against MEKK from Santa Cruz Biotechnology, Inc., (Santa Cruz, CA); okadic acid from Wako Pure Chemical Industries, Ltd., Osaka, Japan; and ProtoBlot immunoblotting system from Promega Biotec (Madison, WI). Other reagents were purchased from Sigma Chemical Co. (St. Louis, MO).

Cell culture and stretching of cardiac myocytes. Primary cultures of cardiac myocytes were prepared from ventricles of 1-d-old Wistar rats as described previously (5), basically according to the method of Simpson et al. (23). Stretching of myocytes was conducted as described previously $(5,6)$. In brief, cardiac myocytes were plated at a field density of $1 \times 10^{5}$ cells $/ \mathrm{cm}^{2}$ on silicone rubber culture dishes. The culture medium was changed $24 \mathrm{~h}$ after seeding to a solution consisting of DME containing $0.1 \%$ FBS. Cardiac myocytes were stretched by $20 \%$, and lysed on ice with buffer A containing $25 \mathrm{mM}$ Tris- $\mathrm{HCl}, 25$ $\mathrm{mM} \mathrm{NaCl}, 1 \mathrm{mM}$ sodium orthovanadate, $10 \mathrm{mM} \mathrm{NaF}, 10 \mathrm{mM}$ sodium pyrophosphate, $10 \mathrm{mM}$ okadic acid, $0.5 \mathrm{mM}$ ethylene glycol-bis (baminoethyl ether) $N, N, N^{\prime}, N^{\prime}$ tetraacetic acid (EGTA), and $1 \mathrm{mM}$ phenyl-methyl sulfonyl fluoride. Stretch and control experiments were carried out simultaneously with the same pool of cells in each experiment to match for temperature, $\mathrm{CO}_{2}$ content, or $\mathrm{pH}$ of the medium between stretched and control cells.

Assay of MAPKKK activity of Raf-1 or MEKK. Both Raf-1 and MEKK have been reported to have MAP kinase kinase kinase (MAPKKK) activity $(13,14)$. MAPKKK activity was assayed by measuring the phosphorylation of recombinant MAPKK fused to glutathione $S$ transferase (rMAPKK) (24). The rMAPKK fusion protein was made by inserting mouse MAPKK1 cDNA into pGEX-2T vector. Total cell lysates or the immunoprecipitates with $20 \mu \mathrm{g} / \mathrm{ml}$ of anti-Raf-1 antibody $(\alpha$-raf) or $10 \mu \mathrm{g} / \mathrm{ml}$ of anti-MEKK antibody were incubated with the substrate (100 $\mu \mathrm{g}$ rMAPKK) and $2 \mu \mathrm{Ci}\left[\gamma-{ }^{32} \mathrm{P}\right] \mathrm{ATP}$ in buffer B containing $25 \mathrm{mM}$ Tris- $\mathrm{HCl}$ ( $\mathrm{pH} 7.4$ ), $10 \mathrm{mM} \mathrm{MgCl}, 1 \mathrm{mM} \mathrm{DTT}, 40 \mu \mathrm{M}$ ATP, $2 \mu \mathrm{M}$ protein kinase inhibitor peptide, and 0.5 mM EGTA for 30 $\min$ at $25^{\circ} \mathrm{C}$. After incubation, rMAPKK was collected using glutathione beads and electrophoresed on a $7 \%$ polyacrylamide gel. The gel was dried and subjected to autoradiography. $\alpha$-raf is an affinity-purified rabbit polyclonal antibody raised against the $\mathrm{COOH}$-terminal 12 amino acid peptide (CTLTTSPRLPVF) of rat Raf-1, which recognizes c-raf, but not B-raf and A-raf (25). Anti-MEKK antibody is also an affinity- purified rabbit polyclonal antibody against the carboxy-terminal 22 amino acids of mouse MEKK and reacts with rat MEKK by immunoblotting and immunoprecipitation (data not shown).

Assay of MAPKK activity. MAPKK activity was assayed using recombinant MAPK fused to maltose binding protein (rMAPK) as described previously (26). In brief, to separate MAPKK from endogenous MAPKs, cell lysates were applied to Q-sepharose column and flowthrough fractions were immunoprecipitated with $25 \mu \mathrm{g} / \mathrm{ml}$ of MAPKK antibody which is an affinity-purified polyclonal antibody raised against the $\mathrm{NH}_{2}$-terminal 16 amino acid peptide (PKKKPTPIQLNPNPEG) of Xenopus MAPKK and termed $\alpha$ nMAPKK $(26,27)$. The immunoprecipitates were incubated with the substrate (100 $\mu \mathrm{g}$ rMAPK) in buffer B for $30 \mathrm{~min}$ at $25^{\circ} \mathrm{C}$. rMAPK was collected using amylose resin and was electrophoresed on a $7 \%$ polyacrylamide gel. The gel was dried and subjected to autoradiography.

Phosphorylation of MAPKs. The extracts of cardiac myocytes were separated by SDS-PAGE. After electrophoresis, the proteins were electrotransferred onto Immobilon-P membrane using a Milli Blot-SDS system (Nihon Millpore Ltd., Tokyo, Japan). The unoccupied protein binding sites on the membrane were blocked by $3 \%$ BSA in buffer containing $10 \mathrm{mM}$ Tris- $\mathrm{HCl}, \mathrm{pH} 7.5,150 \mathrm{mM} \mathrm{NaCl}$, and $0.1 \%$ Triton X-100 for $1 \mathrm{~h}$ at room temperature. The membrane was incubated with $10 \mu \mathrm{g} / \mathrm{ml}$ of anti-MAPK antibody, $\alpha \mathrm{Y} 91$ (28), for $10 \mathrm{~h}$ at $4^{\circ} \mathrm{C} . \alpha \mathrm{Y} 91$ is also an affinity-purified rabbit polyclonal antibody raised against the 21 amino acid sequence deduced from the rat MAPK cDNA (28). After washing, the membrane was incubated for $1 \mathrm{~h}$ with alkaline phosphatase-coupled second antibody, and developed using the ProtoBlot immunoblotting system according to the manufacturer's instructions.

Assays of $p 90^{\text {rst }}$ activity. The activity of $\mathrm{p} 90^{\text {rsk }}$ was measured as previously described $(7,29)$. The immunoprecipitates from the lysates of cardiac myocytes with $10 \mu \mathrm{g} / \mathrm{ml}$ of anti-p90 ${ }^{\text {rsk }}$ antibody ( $\alpha \mathrm{rsk}(\mathrm{m}) \mathrm{c}$ ) (29) or with control preimmune rabbit serum were incubated with 50 $\mu \mathrm{g}$ of S6 peptide (RRLSSLRA) in $25 \mathrm{mM}$ Tris-HCl, pH 7.4, $10 \mathrm{mM}$ $\mathrm{MgCl}_{2}, 1 \mathrm{mM}$ DTT, $40 \mu \mathrm{M}$ ATP, $2 \mu \mathrm{Ci}\left[\gamma-{ }^{32} \mathrm{P}\right] \mathrm{ATP}, 2 \mu \mathrm{M}$ protein kinase inhibitor peptide, and $0.5 \mathrm{mM}$ EGTA. After incubation for 10 min at $25^{\circ} \mathrm{C}, 10 \mu \mathrm{l}$ of stopping solution containing $0.6 \% \mathrm{HCl}, 1 \mathrm{mM}$ ATP, and $1 \%$ BSA was added. After centrifugation, aliquots of the supernatants $(15 \mu \mathrm{l})$ were spotted on $1.5 \times 1.5 \mathrm{~cm}$ squares of P81 paper. The papers were washed five times for at least $10 \mathrm{~min}$ each in $0.5 \%$ phosphoric acid, then in acetone, and dried. The ${ }^{32} \mathrm{P}$ uptake was measured by Cerenkov counting method. $\alpha$ rsk $(m) c$ is also an affinitypurified rabbit polyclonal antibody against the amino acid sequence deduced from the cDNA of mouse S6 kinase II (29).

Phosphorylation of Raf-1. Phosphorylation of Raf-1 protein was examined by Western blot analysis. Myocyte lysates were electrophoresed on a 7\% polyacrylamide gel, blotted onto a nitrocellulose sheet, and incubated with $\alpha$-raf. The immune complexes were detected by the alkaline phosphatase method as described before (7).

Assay of Raf-1 autokinase activity. Cardiac myocytes were lysed in buffer A, and Raf-1 was immunoprecipitated with $\alpha$-raf. The autophosphorylation activity of Raf-1 was assayed by incubating the immunoprecipitates with $10 \mu \mathrm{Ci}\left[\gamma_{-}{ }^{32} \mathrm{P}\right] \mathrm{ATP}$ in $25 \mathrm{mM}$ Tris- $\mathrm{HCl}, \mathrm{pH} 7.4,140$ $\mathrm{mM} \mathrm{NaCl}, 5 \mathrm{mM} \mathrm{MnCl}, 10 \%$ glycerol, and $20 \mu \mathrm{M}$ ATP for $20 \mathrm{~min}$. Samples were separated by SDS-PAGE, and activity was detected by autoradiography.

Kinase assays of $\alpha Y 91$-immunoprecipitates in myelin basic protein (MBP)-containing gels after SDS-PAGE. MAPK activity was measured using MBP-containing gels as described previously (7). In brief, MAPKs were immunoprecipitated with $\alpha \mathrm{Y} 91$ in the presence of $0.15 \%$ of SDS, and was electrophoresed on an SDS-polyacrylamide gel containing $0.5 \mathrm{mg} / \mathrm{ml}$ MBP. MAPKs were denatured by $6 \mathrm{M}$ guanidine/ $\mathrm{HCl}$ and renatured in $50 \mathrm{mM}$ Tris- $\mathrm{HCl}(\mathrm{pH} 8.0)$ containing $0.04 \%$ Tween 40 and $5 \mathrm{mM}$ 2-mercaptoethanol. Phosphorylation of MBP was assayed by incubating the gel with $\left[\gamma-{ }^{32} \mathrm{P}\right]$ ATP. After incubation, the gel was washed extensively, dried, and then subjected to autoradiography.

Amino acid incorporation into myocytes. After cultured in the serum-free medium for $2 \mathrm{~d}$, cardiac myocytes were stretched for $24 \mathrm{~h}$ in 

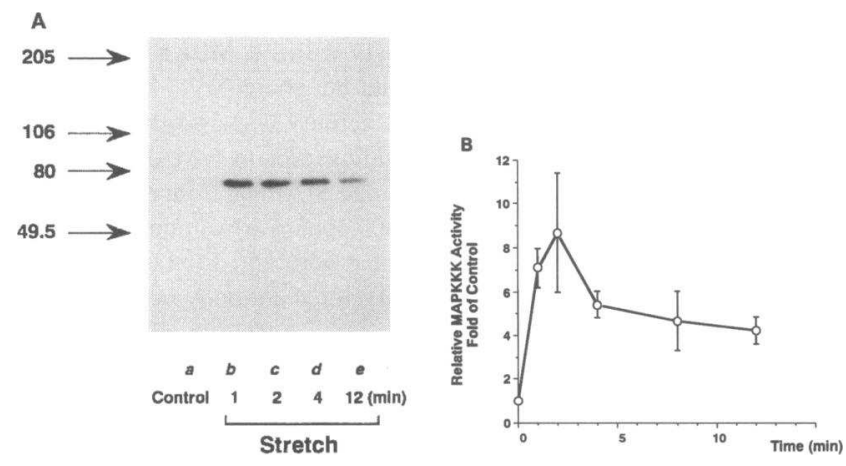

Figure 1. MAPKKK activation by stretch in cardiac myocytes. Cardiac myocytes were stretched by $20 \%$ for the indicated periods of time, and the total cell lysates were subjected to the MAPKKK assay as described in Methods. $(A)$ A representative autoradiogram showing MAPKKK activation by stretch in cardiac myocytes; $(B)$ the time course of MAPKKK activation. Relative kinase activity was determined by scanning each band with a densitometer. The results were indicated as mean $\pm S E$ for five independent experiments. The activity was expressed relative to that obtained in nonstretched myocytes.

the absence or presence of $2 \mathrm{nM}$ staurosporine. The relative amount of protein synthesis was determined by assessing the incorporation of the radioactivity into a trichloroacetic acid-insoluble fraction. $1 \mu \mathrm{Ci} / \mathrm{ml}$ $\left[{ }^{3} \mathrm{H}\right]$ phenylalanine was added to the culture medium $2 \mathrm{~h}$ before harvesting. The cells were rapidly rinsed four times with ice-cold PBS (10 $\mathrm{mM}$ sodium phosphate and $0.85 \% \mathrm{NaCl}, \mathrm{pH} \mathrm{7.4)}$ and incubated for 20 min on ice with $1 \mathrm{ml}$ of $20 \%$ trichloroacetic acid. The total radioactivity in each dish was determined by liquid scintillation counting. We repeated the experiment four times in duplicate.

\section{Results}

Mechanical stress up-regulates MAPKKK activities. We have previously shown that mechanical stress increases the activity of MAPKs (7). MAPKs are reported to be activated by another protein kinase MAPKK $(8-10)$, the activity of which is regulated by MAPKKKs (14). Both Raf-1 and MEKK have been reported to have MAPKKK activity $(13,14)$. To examine the upstream enzyme of MAPKs, the activity of MAPKKKs in total cell lysates was first analyzed by examining the phosphorylation of rMAPKK (Fig. 1, $A$ and $B$ ). We observed a significant increase in the activity of MAPKKKs from as early as $1 \mathrm{~min}$ after stretch compared with the nonstretch control (control, Fig. $1 A$, lane $a$ ), and maximal induction of activity was observed at $2 \mathrm{~min}$ after stretch, with a progressive decline in activity thereafter. The slight increase in activity continued until $12 \mathrm{~min}$, and the levels returned to near control levels by $30 \mathrm{~min}$ (data not shown).

Mechanical stress activates MAPKK. In many cell types, MAPKKKs are reported to phosphorylate and activate MAPKK. In cultured cardiac myocytes of neonatal rats, we examined whether stretching of myocytes also activates MAPKK. Without stretch, MAPKK activity was barely detectable in the cardiocyte lysate (Fig. $2 A$, lane $a$ ). Stretching by $20 \%$ for 1-10 min, however, significantly increased MAPKK activity as shown in lane $b-e$. The activity of MAPKK was quantitated by densitometric scanning and the time course of activation of MAPKK by stretch was shown in Fig. $2 B$. MAPKK activity was increased as early as $1 \mathrm{~min}$ after stretch, maximally activated 5 min after stretch, and gradually decreased
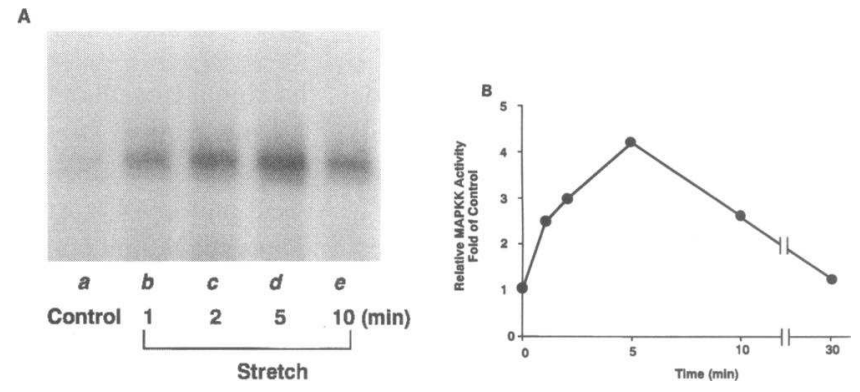

Figure 2. MAPKK activation by stretch. MAPKK activity was assayed using rMAPK as a specific substrate. To separate MAPKK from endogenous MAPKs, cell lysates were applied to Q-sepharose column and flow-through fractions were immunoprecipitated with $\alpha$ nMAPKK antibody (26). The immunoprecipitates were incubated with $100 \mu \mathrm{g}$ rMAPK in buffer B for $30 \mathrm{~min}$ at $25^{\circ} \mathrm{C}$. rMAPK was collected using amylose resin and was electrophoresed on a 7\% polyacrylamide gel. $(A)$ A representative autoradiogram of stretch-induced MAPKK activation in cardiac myocytes; $(B)$ the time course of MAPKK activation. Each band of the autoradiogram was quantified by a densitometer and the activity relative to that in nonstretched myocytes was indicated. The average of two independent experiments was shown.

thereafter. The kinase activity returned to basal levels at $30 \mathrm{~min}$ after stretch (Fig. 2 B).

Mechanical stress phosphorylates and activates MAPKs. $\alpha$ Y91 which recognizes both $42-\mathrm{kD}$ and 44-kD MAPKs in the presence of $0.15 \%$-SDS (28) was used to detect MAPKs in cell lysates from cultured cardiac myocytes. It has been known that MAPKs are activated by phosphorylation and that phosphorylated MAPKs are decreased in the electrophoretic mobility (30). When cardiac myocytes were stretched by $20 \%$ for 1 min, an apparent decrease in electrophoretic mobility of $42-\mathrm{kD}$ MAPK was not observed (Fig. 3, lane $b$ ). The shift of the 42$\mathrm{kD}$ band was first observed at $2 \mathrm{~min}$ after stretch (lane $c$ ). The band was maximally shifted at 10 min (lane $e$ ). The shift gradually decreased thereafter, and returned to control levels at 60 min after stretch (data not shown). We also measured the MAPK activity using MBP-containing gels. MAPK activity was also maximally increased $8 \mathrm{~min}$ after stretch and returned to control levels at $60 \mathrm{~min}$ after stretch (reference 7, data not shown). This observation is consistent with the notion that phosphorylation of MAPKs reflects their activation (11).

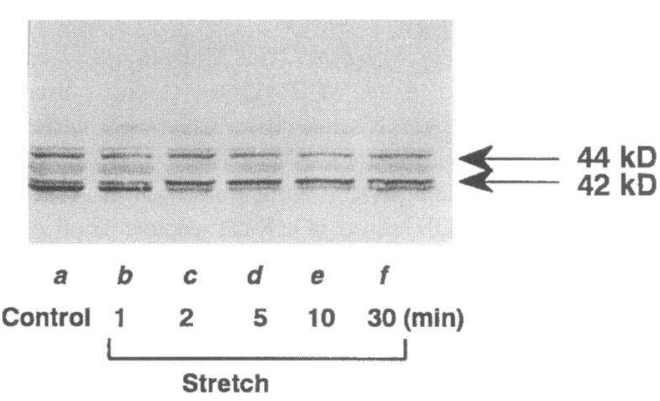

Figure 3. Phosphorylation of MAPKs by stretch. Phosphorylation of MAPKs was demonstrated by a shift in the electrophoretic mobility. Cells were stretched by $20 \%$ for the indicated periods of time, and the cell lysates were subjected to Western blot analysis with an anti-MAPKs antibody, $\alpha$ Y91 as described in Methods. Similar results were obtained in three independent experiments. 


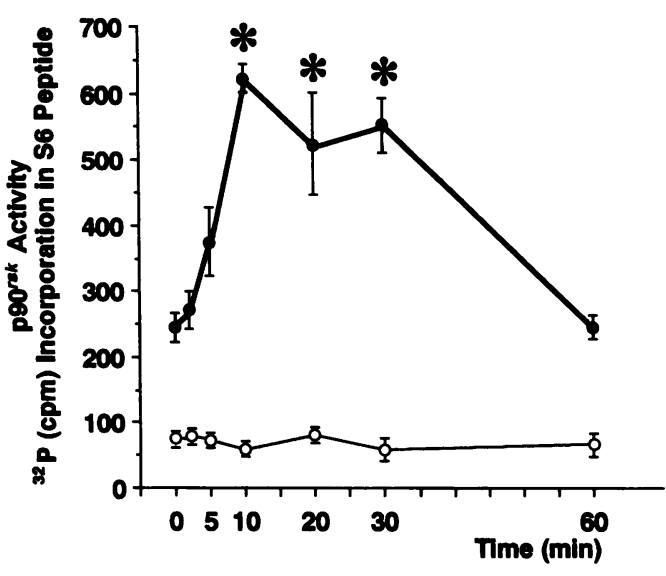

Figure 4. Stretch-induced $\mathrm{p} 90^{\text {rsk }}$ activation in cardiac myocytes. Cardiac myocytes were stretched by $20 \%$ for the indicated periods of time and cell lysates were subjected to immunoprecipitation with $\alpha \mathrm{rsk}(\mathrm{m}) \mathrm{C}$ (closed circles) or control serum (open circles), followed by kinase assay using S6 synthetic peptide as a substrate. The results were shown as mean $\pm \mathrm{SE}$ for four independent experiments. Asterisks mean significant $(P<0.05)$ increase in $\mathrm{p} 90^{\text {rsk }}$ activity compared with 0 time control.

Mechanical stress activates $p 90^{r s k}$. MAPKs phosphorylate and activate $\mathrm{p} 90^{\text {rsk }}$, a cytosolic kinase that can phosphorylate the nuclear lamins (18). Our preliminary data showed that stretching of myocytes for $10 \mathrm{~min}$ increases $\mathrm{p} 90^{\text {rk }}$ activity (7). In the present study, we extensively examined the time course of stretch-induced $\mathrm{p} 90^{\text {rsk }}$ activation (Fig. 4). The activation was not observed at 2 min after stretch. The increase in activity was first detectable at $5 \mathrm{~min}$, peaked at $10 \mathrm{~min}$, and sustained higher levels for at least $30 \mathrm{~min}$ after stimulation. At the 60 -min time point, the activity returned to the basal level.

Taken together, both initial and maximal activation of MAPKKKs, MAPKK, MAPKs, and $\mathrm{p} 90^{\text {rsk }}$ was observed in this order after stretch stimulation, suggesting that like growth factor-induced signaling cascade in noncardiac cells, the stretch-induced protein kinase cascade spreads in cardiac myocytes in the order of MAPKKKs, MAPKK, MAPKs, and $\mathrm{p} 90^{\text {rsk }}$.

Mechanical stress phosphorylates and activates Raf-1. Since activation of MAPKKKs triggers the protein kinase cascade of phosphorylation of MAPKs and $\mathrm{p} 90^{\text {rsk }}$ through MAPKK, we further characterized MAPKKK activation by mechanical stress. Raf-1 has been reported to have a MAPKKK activity and to be activated by phosphorylation, which can be detected by its shift of electrophoretic mobility $(13,15)$. We therefore examined hyperphosphorylation of Raf-1 by Western blotting using $\alpha$-raf. Although there was no significant change in the mobility of Raf-1 in cardiac myocytes stretched for 0.5 or $1 \mathrm{~min}$ (Fig. 5, lane $b$ and $c$ ), Raf-1 molecules in stretched cells for 2-10 min (lane $d-f$ ) migrated more slowly than the Raf-1 molecules in the unstimulated cells (lane $a$ ), suggesting that mechanical stretch hyperphosphorylated Raf-1. The mobility of Raf-1 returned to the control level at $30 \mathrm{~min}$ after stretch (lane $g$ ).

Since the hyperphosphorylation of Raf-1 could have two meanings, activation and feedback inhibition of Raf-1 (26), we examined whether mechanical stress activates Raf-1. First, we examined Raf- 1 autokinase activity. Raf-1 was immunoprecipitated with $\alpha$-raf from the lysates of stretched myocytes and incubated with $\left[\gamma-{ }^{32} \mathrm{P}\right]$ ATP in vitro. Stretching for 1 to $2 \mathrm{~min}$

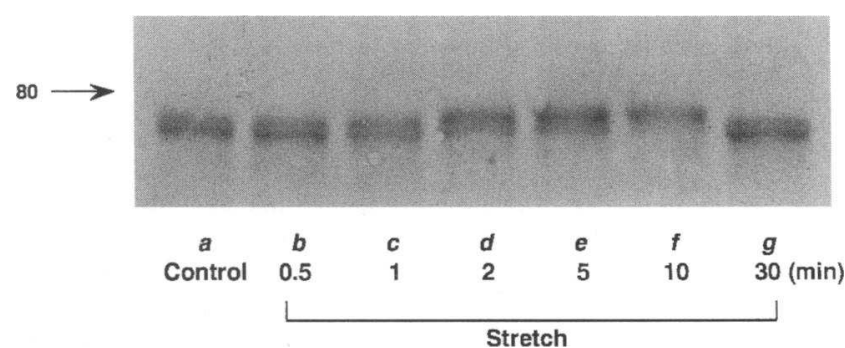

Figure 5. Stretch-induced Raf-1 phosphorylation. Cardiac myocytes were stretched by $20 \%$ for the indicated periods of time. Total cell lysates were electrophoresed on a 7\% polyacrylamide gel and transferred to nitrocellulose filters. Protein blots were probed with $\alpha$-raf. Essentially, similar results were obtained in three independent experiments.

increased Raf-1 autokinase activity as shown in Fig. 6 A. Autokinase activity of Raf-1 peaked at $1 \mathrm{~min}$ and returned to the control level $12 \mathrm{~min}$ after stretch (Fig. 6, $A$ and $B$ ). Secondly, we examined Raf- 1 activity using rMAPKK as a substrate. The immunoprecipitates with $\alpha$-raf were incubated with rMAPKK and $\left[\gamma{ }^{32} \mathrm{P}\right] \mathrm{ATP}$, and the incorporation of ${ }^{32} \mathrm{P}$ into rMAPKK was examined. A rapid increase in MAPKKK activity was observed in the $\alpha$-raf immunoprecipitates from stretched cells for 2 min (Fig. 7, lane $b$ ), indicating that mechanical stretch increased the MAPKKK activity of Raf- 1 .

Stretch-induced activation of Raf-1 occurs via PKC-dependent and independent pathways. We have previously reported that mechanical stress induces MAPK activation via both PKCdependent and independent pathways (7). It has been reported in other cells that there are also two pathways for Raf-1 activation, PKC-dependent and independent pathways (15). We therefore examined whether Raf-1 activation by stretching of cardiac myocytes is associated with the activation of PKC. When myocytes were pretreated with $10^{-7} \mathrm{M} 12-O$-tetradecanoylphorbol-13-acetate (TPA) for $24 \mathrm{~h}$, TPA itself failed to activate Raf-1 activity, suggesting that phorbol ester-sensitive PKC was completely depleted (data not shown). In these pretreated cardiocytes, activation of Raf- 1 by stretch was decreased by $\sim 50 \%$ as compared with the kinase activity in stretched myocytes without pretreatment (Fig. 7, lane $b$ and $c$ ). Since the stretch-induced MAPK activation was also partially sup-
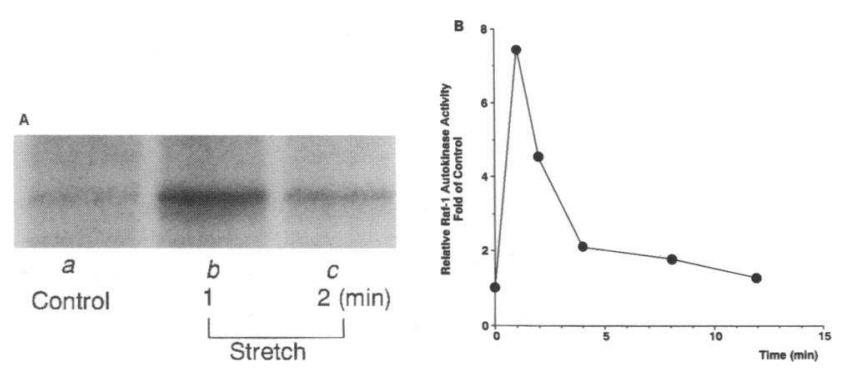

Figure 6. Raf-1 autokinase activation by stretch. $(A)$ Cardiac myocytes were stretched by $20 \%$ for the indicated periods of time. The immunoprecipitates with $\alpha$-raf were incubated with $10 \mu \mathrm{Ci}\left[\gamma-{ }^{32} \mathrm{P}\right]$ ATP for 20 min at $25^{\circ} \mathrm{C}$, electrophoresed on a $7 \%$ polyacrylamide gel, and the gel was subjected to autoradiography. B, the intensity of 76-kD band corresponding to Raf-1 was measured by densitometric scanning of the autoradiogram. Values represent the mean values from three independent experiments. The intensity of $76-\mathrm{kD}$ Raf-1 band of nonstretched myocytes was designated as 1.0 . 


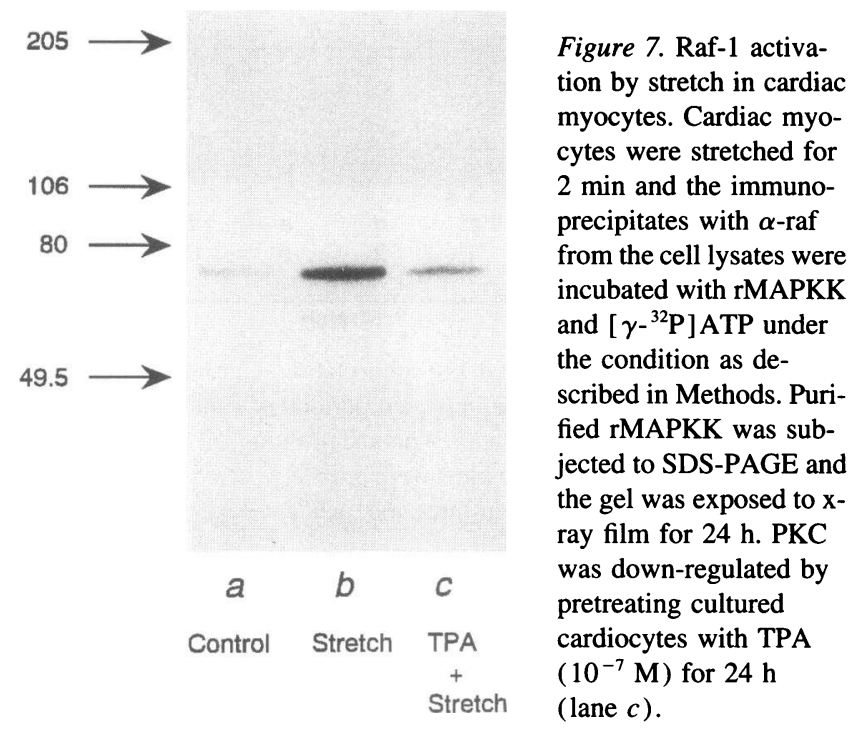

pressed by the down-regulation of PKC (7), there may be two pathways, PKC-dependent and independent pathways, in stretch-induced signaling cascade of protein kinases and the two pathways may converge at the level of Raf- 1 .

Stretch-induced activation of Raf-1 and MAPKs is partially dependent on external Ang II. Recently, it has been reported that Ang II is secreted from cardiac myocytes by stretch (31), and our preliminary data suggest that the increase in MAPK activity and c-fos gene expression by stretch are dependent on Ang II (32). We therefore examined the role of Ang II in the mechanical stress-induced signaling cascade. When cardiac myocytes were incubated with $10^{-7} \mathrm{M}$ Ang II for $2 \mathrm{~min}$, significant activation of Raf-1 was observed (Fig. 8, Ang II). This activation was completely suppressed by pretreatment with $10^{-6}$ M Ang II type 1 receptor-specific antagonist, CV-11974 $(C V-11974+$ Ang II), suggesting that Raf-1 is activated by Ang II through type 1 receptor. Next, after pretreatment with CV-11974 $\left(10^{-6} \mathrm{M}\right)$ for $30 \mathrm{~min}$, cardiac myocytes were stretched by $20 \%$ for 2 min. Stretch-induced Raf- 1 activation was partially inhibited by pretreatment with CV-11974

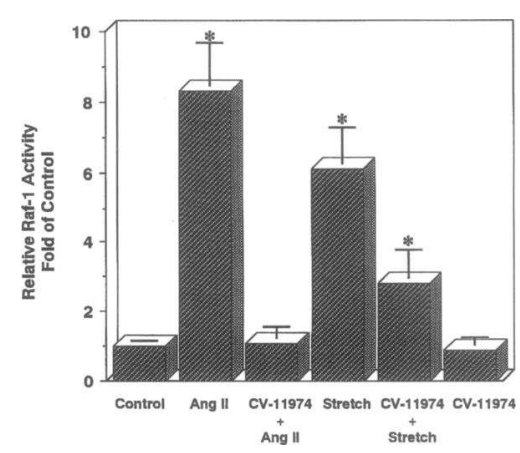

Figure 8. Partial dependence of stretch-induced Raf-1 activation on Ang II. Cardiac myocytes were stimulated by Ang II $\left(10^{-7} \mathrm{M}\right)$ for $2 \mathrm{~min}$ or stretched for 2 min without or with the pretreatment by Ang II-type 1 receptor antagonist, $\mathrm{CV}$ $11974\left(10^{-7} \mathrm{M}\right)$ for 30 min. After immunoprecipitated by $\alpha$-raf, Raf- 1 was incubated with

rMAPKK and $\left[\gamma_{-}{ }^{32} \mathrm{P}\right]$ ATP. Purified rMAPKK was subjected to SDSPAGE and the gel was subjected to autoradiography. Relative kinase activity was determined by scanning each band with a densitometer. The results were indicated as mean $\pm \mathrm{SE}$ for four independent experiments. The activity was expressed relative to that obtained in nontreated myocytes. Asterisks mean a significant $(P<0.05)$ increase in MAPK activity compared with control.
A

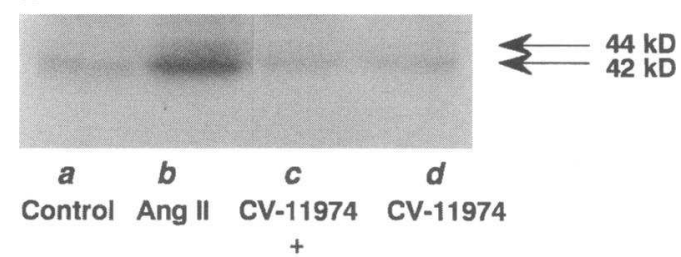

$\stackrel{+}{+}$

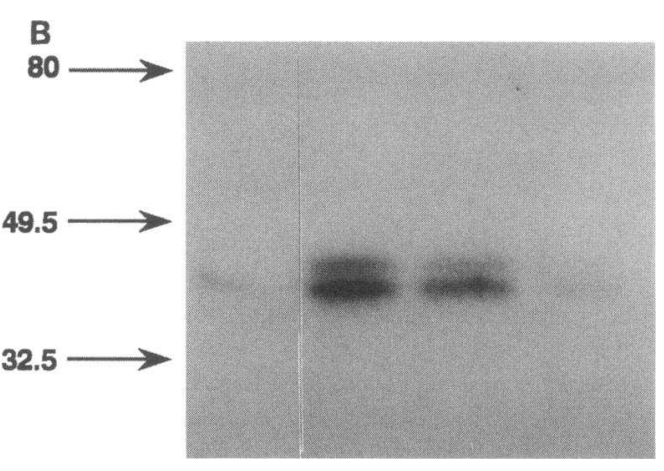

$\begin{array}{lllll}a & b & c & d\end{array}$

Control Stretch CV-11974 CV-11974

$+$

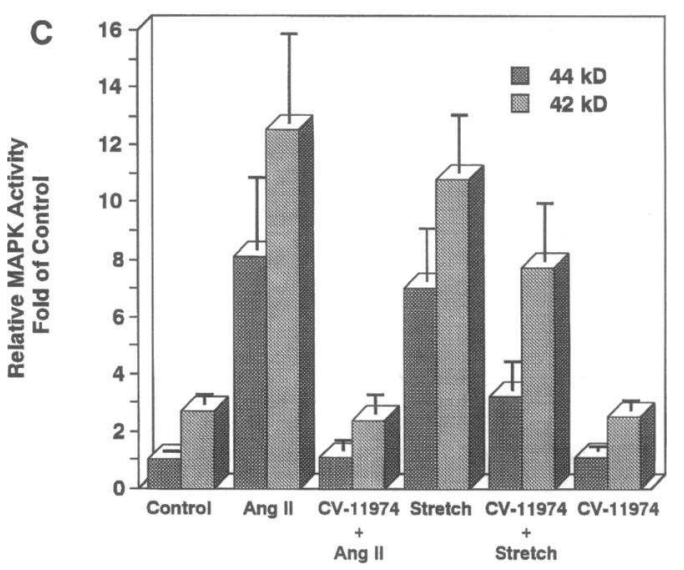

Figure 9. Partial dependence of stretch-induced MAPK activation on Ang II. Cardiac myocytes were stimulated by Ang II $\left(10^{-7} \mathrm{M}\right)$ for 8 $\min (A)$ or stretched by $20 \%$ for $8 \mathrm{~min}(B)$ with (lane $c$ ) or without (lane $b$ ) the pretreatment by CV-11974 $\left(10^{-6} \mathrm{M}\right)$ for $30 \mathrm{~min}$. MAPKs were immunoprecipitated with $\alpha$ Y91 and electrophoresed on a SDSpolyacrylamide gel containing MBP. After denaturation and renaturation, the gel was incubated with $\left[\gamma_{-}{ }^{32} \mathrm{P}\right] \mathrm{ATP}$. The gel was washed, dried, and subjected to autoradiography. Lane $a$, nonstretch; lane $d$ nonstretch with CV-11974. (C) The intensities of 42-kD and 44-kD bands were measured by densitometric scanning of the autoradiogram. Values represent the mean $\pm \mathrm{SE}$ from four independent experiments. The intensity of 44-kD MAPK of nonstretched myocytes was designated as 1.0.

(CV-11974 + Stretch), indicating that a part of Raf-1 activation by mechanical stretch is dependent on Ang II.

The involvement of Ang II in stretch-induced MAPK activation was also examined by kinase assays using MBP-containing gels (32). Incubation with $10^{-7} \mathrm{M}$ Ang II for 8 min evoked maximal activation of both $42-\mathrm{kD}$ and $44-\mathrm{kD}$ MAPKs in cardiac 

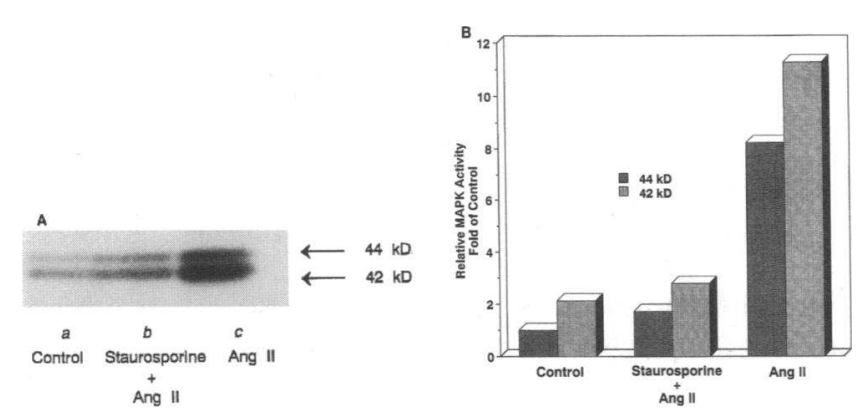

Figure 10. Dependence of Ang II-induced MAPK activation on PKC. $(A)$ Cardiac myocytes were stimulated by $10^{-6} \mathrm{M}$ Ang II for $8 \mathrm{~min}$ in the presence (lane $b$ ) or absence (lane $c$ ) of pretreatment with $2 \mathrm{nM}$ staurosporine for $30 \mathrm{~min}$. The immunoprecipitates with an anti-MAPKs antibody, $\alpha$ Y91, were subjected to MAPK assays in MBP-containing gels as described in Methods. $(B)$ The intensities of $42-\mathrm{kD}$ and $44-\mathrm{kD}$ bands were measured by densitometric scanning of the autoradiogram. Values represent the mean values from three independent experiments. The intensity of 44-kD MAPK of nonstretched myocytes was designated as 1.0.

myocytes, and activation was completely blocked by $10^{-6} \mathrm{M}$ CV-11974 (Fig. 9, A and C, Ang II vs CV-11974 + Ang II). This result suggests that like Raf-1 activation, MAPKs are activated by Ang II through type 1 receptor. Stretch-induced MAPK activation was suppressed by only $50-70 \%$ by the pretreatment with CV-11974 $\left(10^{-6} \mathrm{M}\right.$ ) for $30 \mathrm{~min}$ (Fig. $9 B$ lane $b$ and $c$; Fig. 9 C Stretch vs $C V-11974+$ Stretch), which is consistent with our previous results (32). Addition of CV-11974 did not activate MAPK activity by itself (Fig. $9 A$, lane $d$; and Fig. 9 $B$, lane $d$ ). Pretreatment with Ang II type 2-receptor antagonist, PD123319, had no effect on stretch-induced activation of Raf1 and MAPKs (data not shown). These results suggest that there are two transduction pathways for mechanical stress, Ang II-dependent (through type 1 receptor) and independent pathways.

Ang II-induced MAPK activation is dependent on PKC. We have previously shown that a PKC inhibitor, $2 \mathrm{nM}$ staurosporine, which completely abolished the effect of $10^{-6} \mathrm{M}$ TPA, partially suppressed the activation of MAPKs induced by stretch (7). Taken together, these results suggest that both PKC and external Ang II are involved in part in stretch-induced activation of the signaling pathway from Raf-1 to MAPKs. Then we examined the relationship between PKC and Ang II. We analyzed the effect of PKC on MAPK activation by Ang II using a PKC inhibitor, staurosporine. As shown in Fig. 10, $A$ and $B$, Ang II $\left(10^{-6} \mathrm{M}\right)$ increased the activity of both $42-\mathrm{kD}$ and $44-\mathrm{kD}$ MAPKs, which was almost completely blocked by pretreatment with staurosporine ( $2 \mathrm{nM}$ for $30 \mathrm{~min}$ ). Addition of TPA $\left(10^{-6}\right.$ M) did not activate MAPK activity on this condition. Similar results were obtained using PKC-down-regulated cardiac myocytes (data not shown). Taken together, these results suggest that while there are two pathways, PKC-dependent and independent, for stretch-induced protein kinase cascade of phosphorylation, Ang II-induced signaling pathways are triggered mainly by the activation of PKC.

Stretch causes MEKK activation. Recently, MEKK as well as Raf-1 has been reported to activate $\operatorname{MAPKK}(13,14)$. We examined whether stretch can also induce MEKK activation in cardiac myocytes. Although the nonstretched myocytes showed

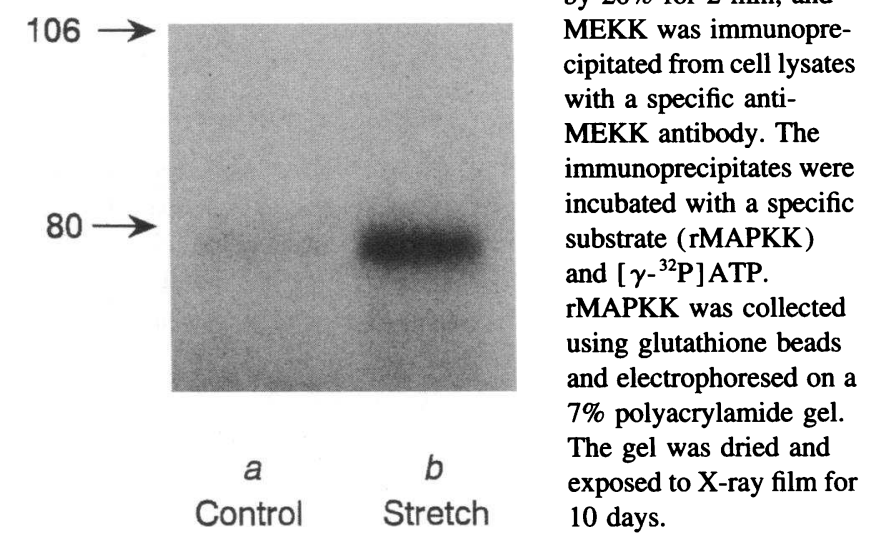

almost no activity of MEKK (Fig. 11, lane $a$ ), stretch for 2 min dramatically increased the activity of MEKK (lane $b$ ), suggesting that not only Raf-1 but also MEKK is activated during mechanical stretch-induced hypertrophy.

Stretch induces an increase in phenylalanine incorporation into myocytes via both PKC-dependent and independent pathways. We have previously shown that stretching of myocytes increases phenylalanine incorporation into cells, suggesting that mechanical stress directly induces cardiac cellular hypertrophy $(5,6)$. To examine whether PKC is involved in stretch-induced cardiac hypertrophy, we measured the relative amount of protein synthesis after stretch in the presence or absence of staurosporine. As shown in Fig. 12, stretch by $20 \%$ for $24 \mathrm{~h}$ stimulated an amino acid incorporation by $\sim 1.5$-fold. This increase was only partially suppressed by pretreatment with $2 \mathrm{nM}$ staurosporine. These data suggest that the cellular hypertrophy is also induced by mechanical stress both through PKC-dependent and independent pathways.

\section{Discussion}

In the present study, we investigated the signaling pathways which are evoked by mechanical stress in neonatal rat cardiac myocytes. Stretching of cardiac myocytes sequentially activated

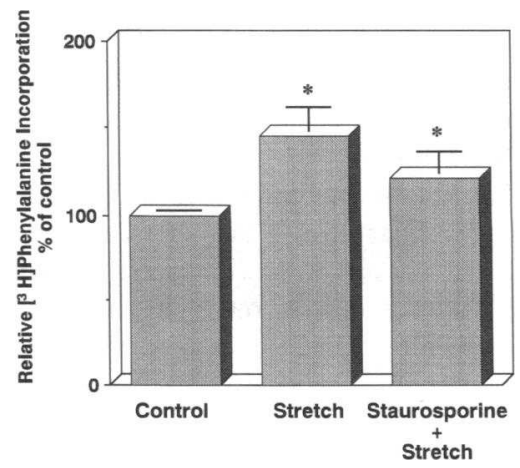

Figure 12. Partial dependence of stretch-evoked phenylalanine incorporation on PKC. After pretreatment with staurosporine $(2 \mathrm{nM})$ for 30 min, cardiac myocytes were stimulated by stretch for $24 \mathrm{~h}$ and $\left[{ }^{3} \mathrm{H}\right]$ phenylalanine ( 1 $\mu \mathrm{Ci} / \mathrm{ml}$ ) was added $2 \mathrm{~h}$ before harvest. The total radioactivity of incorporated $\left[{ }^{3} \mathrm{H}\right]$ phenylalanine into proteins was determined by liquid scintillation counting. The relative phenylalanine uptake was shown as mean $\pm S E$ from four independent experiments. $\left({ }^{*} P<0.05\right.$ vs control $)$. 
protein kinase cascade of phosphorylation. Both initial and maximal activation occurred in the order of MAPKKK, MAPKK, MAPKs, and $\mathrm{p} 90^{\text {rsk }}$. It has been reported that MAPKs translocate into the nucleus upon activation and activate transcription factors which contain potential MAPK phosphorylation sites (16). We have previously shown that mechanical loading induces expression of immediate early response genes such as c-myc and c-fos genes as an early event $(3,5,33)$. Therefore, once an extracellular signal, mechanical stress, is received by cardiac myocytes, the signal may spread in cardiac myocytes by protein kinase cascade in the order of MAPKKKs $\rightarrow$ MAPKK $\rightarrow$ MAPKs $\rightarrow$ p $90^{\text {rsk }}$ and may evoke the nuclear events (gene expression). In addition, we have previously shown that c-fos was abundantly expressed in cardiac myocyte-rich fraction rather than in nonmuscle-rich fraction (5) and that stretching of cardiac myocytes for $24 \mathrm{~h}$ increased total RNA content by $45 \%$, while RNA content in the nonmuscle-rich fraction was not increased by stretch (6). These results suggest that the stimulation of gene expression and hypertrophic responses by stretch mainly occurs in cardiac myocytes although Ang II whose secretion is induced by stretch from cardiac myocytes may act on nonmuscle cardiocytes by a paracrine mechanism.

MAPKKKs, in general, have been implicated as transduction signaling molecules in the cytoplasm upstream of MAPKs and downstream of other molecules such as Ras, PKC, and Src (14). It has been reported that both Raf-1 and MEKK have a MAPKKK activity and can phosphorylate and activate MAPKK $(13,14)$. In other words, signal transduction pathways from Raf-1 and MEKK converge at MAPKK resulting in the activation of MAPKs. There have been many reports in yeast and other mammalian cells suggesting that Raf- 1 may regulate the MAPK network primarily in response to receptors that are associated with tyrosine kinase activity and that MEKK might mediate primary signals originating from receptors that activate $G$ proteins and PKC $(34,35)$. To clarify the upstream signals, we examined which protein kinase, Raf-1 or MEKK, is activated in stretched myocytes. We demonstrated for the first time that stretching of myocytes activates both Raf- 1 and MEKK in a similar time course. The maximum activation of both Raf-1 and MEKK was observed as early as 2 min (Figs. 7 and 11). These results may imply that stretching of cardiac myocytes activates multiple signal transduction pathways such as tyrosine kinases, $\mathrm{G}$ proteins, and PKC, which is consistent with the previous report (36). Although it is difficult to compare the activities of two different kinases, since much more ( $\sim$ fivefold) activation of Raf-1 was observed compared with that of MEKK by mechanical stress in cardiac myocytes, Raf- 1 was used for further analyses.

It has been recently reported that PKC $\alpha$ activates Raf- 1 as well as MEKK by direct phosphorylation and that the phosphorylated site of Raf- 1 by PKC $\alpha$ differs from that by the $\mathrm{p} 21^{\text {ras }}$. mediated signal (37). It has also been shown that 1, 25-dihydroxy vitamin D3 actually stimulates Raf-1 via a PKC-dependent pathway (38). In the present study, we demonstrated that mechanical stress activates Raf- 1 in cardiac myocytes. Stretching of cardiac myocytes hyperphosphorylated Raf-1 (Fig. 5), and increased Raf-1 autokinase (Fig. 6) and MAPKK phosphorylation activities (Fig. 7). This Raf-1 activation by mechanical stress was partially suppressed by PKC down-regulation (Fig. 7). In many cell types, a variety of mitogens activate $\mathrm{p} 21^{\text {ras }}$ and Raf- 1 , and the inhibition of $\mathrm{p} 21^{\text {ras }}$ function abolishes activation of Raf- 1 by mitogens (39), suggesting that $\mathrm{p} 21^{\text {ras }}$ exists upstream of Raf-1 in the signal transduction pathway. Recently, p21 ${ }^{\text {ras }}$ has been reported to be activated in cardiac myocytes by mechanical stress (36). Taken together, the PKC-independent activation of Raf-1 by cardiocyte stretch may be induced through $\mathrm{p} 21^{\text {ras }}$ activation.

Although there is no direct evidence proving that the MAPK cascade is involved in the stretch-induced hypertrophic responses, many studies in noncardiac cells as well as cardiac cells suggest that MAPK cascade play a critical role in growth responses. Thorburn et al. (40) showed that phenylephrine induced the gene expression of atrial natriuretic factor in the cardiocytes and this induction depends on the activation of MAPKs. MAPK has been reported to phosphorylate many proteins including c-myc, c-jun and p62 ${ }^{\mathrm{TCF}}$ (c-fos) which are known to be activated during cardiac hypertrophy $(2,16)$. Ras which is one of upstream signaling molecules for MAPK cascade has been shown to be necessary and sufficient for hypertrophic response (41). These observations raise the possibility that the MAPK cascade may be important in the hypertrophic response of the heart. Development of specific MAPK inhibitors or dominant negative MAPK mutants would elucidate this possibility.

Recent evidence has suggested that Ang II plays an important role in cardiac hypertrophy (20-22). Ang II shows direct stimulatory effects on increased protein synthesis in cultured cardiac myocytes $(42,43)$. Ang II infusion at subpressor doses induces left ventricular hypertrophy in adult rats (44), and cardiac hypertrophy of spontaneous hypertensive rats is prevented by low doses of an Ang II type 1 receptor antagonist (32). Moreover, hypertrophic events such as specific gene expression and activation of PKC and MAPKs induced by mechanical loading resemble those induced by Ang II (5-7). It has been reported that mechanical stretch induces secretion of Ang II from cardiocytes (31). In the present study, stretchinduced activation of Raf-1 and MAPKs was in part inhibited by pretreatment with a type 1 Ang II receptor antagonist. Since the amount of the antagonist used in the present study was sufficient to suppress the maximal effect of Ang II, other factors different from Ang II may be involved in Raf-1 and MAPK activation.

Mechanical stress induced Raf- 1 activation, which was in part suppressed by the down-regulation of PKC (Fig. 7). In the previous paper, we have shown that activation of MAPKs by stretch was also only partially suppressed by a PKC inhibitor, staurosporine (7). On the contrary, Ang II-evoked activation of Raf-1 and MAPK, and the increase in c-fos mRNA expression and protein synthesis were completely blocked by PKC down-regulation or staurosporine (Fig. 10, $A$ and $B$ and reference 43 ). Although the signals evoked by mechanical stress mimic those by Ang II, there are some differences in the signal transduction pathways between mechanical stress and Ang II. In short, mechanical stress activates MAPK cascade both via PKC-dependent and independent pathways, while MAPK activation by Ang II is mostly dependent on a PKC pathway.

The protein kinase cascade activated by mechanical stress is composed of PKC, Raf-1, MEKK, MAPKK, MAPKs, and $\mathrm{p}^{\text {rsk }}$ (Fig. 13). Stretch stimulus induces the activation of Raf1 and MEKK in cardiac myocytes. A part of Raf-1 activation was dependent on Ang II via a PKC-dependent pathway. Once Raf-1 and MEKK are activated, activation of MAPKK, MAPKs, and $\mathrm{p} 90^{\text {rsk }}$ occurs serially in this order. It remains unknown at present whether stretch-induced MEKK activation is associated 


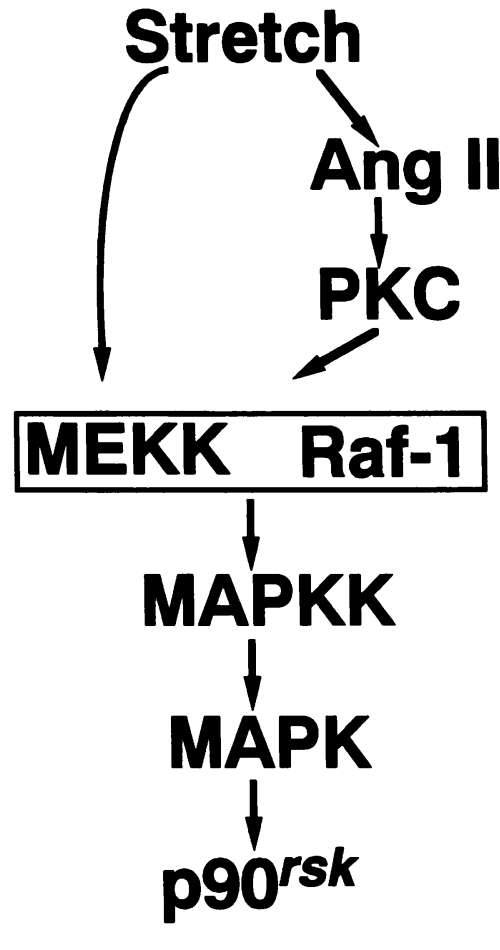

Figure 13. A model for the signal transduction cascade activated by mechanical stress in cardiac myocytes. Mechanical stretch induces secretion of Ang II from cardiac myocytes. Ang II activates PKC and then induces the sequential activation of protein kinases (Raf-1 $\rightarrow$ MAPKK $\rightarrow$ MAPK $\rightarrow$ p90 $\left.{ }^{\text {rsk }}\right)$. There might be other unknown pathways for activating Raf-1. MEKK is also activated by stretch in cardiac myocytes.

with external Ang II or PKC. Our findings highlight the complex and specific signaling pathways of stretch-induced cardiac myocyte hypertrophy. These stretch-induced signal transduction pathways in cardiac myocytes have similarities in some aspects to those of cells which are exposed to hyperosmotic shock. Hyperosmotic shock causes activation of Pbs2 (a member of MAPKK), Hog1 (45), p38 (46) and Jnk (47) (members of the MAPK family) in the yeasts (Pbs2, Hog1) and in mammalian cells ( $\mathrm{p} 38$, Jnk). These observations suggest that the signaling pathways evoked by mechanical stress, if hyperosmotic shock were a kind of mechanical stress, might be highly conserved in evolution and that the transduction of external mechanical stress into the nucleus is quite important for living cells. Further studies are necessary to elucidate the mechanisms by which the mechanical stimulus is converted into these biochemical events and to determine upstream molecules including "'mechanoreceptors," which activate PKC, Raf-1, and MEKK (48).

\section{Acknowledgments}

We thank Toru Suzuki for critical reading, and Fumiko Harima and Megumi Fukuda for the excellent technical assistance. We acknowledge Takeda Chemical Industries, Ltd. (Osaka, Japan) for providing CV11974.

This work was supported by a grant-in-aid for scientific research and developmental scientific research from the Ministry of Education, Science and Culture, a grant from the Japan Cardiovascular Foundation, the Sankyo Life Science and the Study Group of Molecular Cardiology (to I. Komuro), Japan, and a grant from Japan Heart Foundation Research Grant For 1994 (to T. Yamazaki), Japan.

\section{References}

1. Levy, D., R. J. Garrison, D. D. Savage, W. B. Kannel, and W. P. Castelli. 1990. Prognostic implications of echocardiographically determined left ventricular mass in the Framingham heart study. N. Engl. J. Med. 322:1561-1566.
2. Komuro, I., and Y. Yazaki. 1993. Control of cardiac gene expression by mechanical stress. Annu. Rev. Physiol. 55:55-75.

3. Komuro, I., M. Kurabayashi, F. Takaku, and Y. Yazaki. 1988. Expression of cellular oncogenes in the myocardium during the developmental stage and pressure overload hypertrophy of the rat heart. Circ. Res. 62:1075-1079.

4. Mulvagh, S. L., L. H. Michael, M. B. Perryman, R. Roberts, and M. D. Schneider. 1987. A hemodynamic load in vivo induces cardiac expression of the cellular oncogene, c-myc. Biochem. Biophys. Res. Commun. 147:627-36.

5. Komuro, I., T. Kaida, Y. Shibazaki, M. Kurabayashi, F. Takaku, and Y. Yazaki. 1990. Stretching cardiac myocytes stimulates proto-oncogene expression. J. Biol. Chem. 265:3595-3598.

6. Komuro, I., Y. Katoh, T. Kaida, Y. Shibazaki, M. Kurabayashi, F. Takaku, and Y. Yazaki. 1991. Mechanical loading stimulates cell hypertrophy and specific gene expression in cultured rat cardiac myocytes. J. Biol. Chem. 266:1265-1268.

7. Yamazaki, T., K. Tobe, E. Hoh, K. Maemura, T. Kaida, I. Komuro, H. Tamemoto, T. Kadowaki, R. Nagai, and Y. Yazaki. 1993. Mechanical loading activates mitogen-activated protein kinase and S6 peptide kinase in cultured rat cardiac myocytes. J. Biol. Chem. 268:12069-12076.

8. Gomez, N., and P. Cohen. 1991. Dissection of the protein kinase cascade by which nerve growth factor activates MAP kinases. Nature (Lond.). 353:170173.

9. Ahn, N. G., R. Seger, R. L. Bratlien, C. D. Diltz, N. K. Tonks, and E. G. Krebs. 1991. Multiple components in an EGF-stimulated protein kinase cascade. In vitro activation of a MBP/MAP2 kinase. J. Biol. Chem. 266:4220-4227.

10. Matsuda, S., H. Kosako, K. Takenaka, K. Moriyama, H. Sakai, T. Akiyama, Y. Gotoh, and E. Nishida. 1992. Xenopus MAP kinase activator: identification and function as a key intermediate in the phosphorylation cascade. $E M B O$ (Eur. Mol. Biol. Org.) J. 11:973-982.

11. Nishida, E., and Y. Gotoh. 1993. The MAP kinase cascade is essential for diverse signal transduction pathways. Trends Biochem. Sci. 18:128-131.

12. Zheng, C.-F., and K.-L. Guan. 1994. Activation of MEK family kinase requires phosphorylation of two conserved Ser/Thr residues. EMBO (Eur. Mol. Biol. Org.) J. 13:1123-1131.

13. Kyriakis, J. M., H. App, X. Zhang, P. Banerjee, D. L. Brautigan, U. R. Rapp, and J. Avruch. 1992. Raf-1 activates MAP kinase-kinase. Nature (Lond.). 358:417-421.

14. Lange-Carter, C. A., A. M. Pleiman, K. J. Blumer, and G. L. Johnson. 1993. A divergence in the MAP kinase regulatory network defined by MEK kinase and Raf. Science (Wash. DC). 260:315-319.

15. Wood, K. W., C. Sarnecki, T. M. Roberts, and J. Blenis. 1992. Ras mediates nerve growth factor receptor modulation of three signal-transducing protein kinases: MAP kinase, Raf-1 and RSK. Cell. 68:1041-1050.

16. Davis, R. J. 1993. The mitogen-activated protein kinase signal transduction pathway. J. Biol. Chem. 268:14553-14556.

17. Sturgill, T. W., L. B. Ray, E. Erickson, and J. L. Maller. 1988. Insulinstimulated MAP-2 kinase phosphorylates and activates ribosomal protein S6 kinase II. Nature (Lond.). 334:715-718.

18. Ward, G. E., and M. W. Kirschner. 1990. Identification of cell cycleregulated phosphorylation sites on nuclear lamin C. Cell. 61:561-577.

19. Baker, K. M., G. W. Booz, and D. E. Dostal. 1992. Cardiac actions of angiotensin II: role of an intracardiac renin-angiotensin system. Annu. Rev. Physiol. 54:227-241.

20. Linz, W., B. A. Schoelkens, and D. Ganten. 1989. Converting enzyme inhibitor specifically prevents development and induces the regression of cardiac hypertrophy in rats. Clin. Exp. Hypertens. 11:1325-1350.

21. Baker, K. M., M. I. Cherin, S. K. Wixon, and J. F. Aceto. 1990. Reninangiotensin system involvement in pressure-overload cardiac hypertrophy in rats. Am. J. Physiol. 259:H324-H332.

22. Schunkert, H., V. J. Dzau, S. S. Tang, A. T. Hirsch, C. S. Apstein, and B. H. Lorell. 1990. Increased rat cardiac angiotensin converting enzyme activity and mRNA expression in pressure overload left ventricular hypertrophy: effect on coronary resistance, contractility, and relaxation. J. Clin. Invest. 86:19131920.

23. Simpson, P., and S. Savion. 1982. Differentiation of rat myocytes in single cell cultures with and without proliferating nonmyocardial cells. Circ. Res. 50:101-116.

24. Crews, C. M., A. Alessandrini, and R. L. Erikson. 1992. The primary structure of MEK, a protein kinase that phosphorylates the ERK gene product. Science (Wash. DC). 258:478-480.

25. Izumi, T., H. Tamemoto, M. Nagao, T. Kadowaki, F. Takaku, and M. Kasuga. 1991. Insulin and platelet derived growth factor stimulate phosphorylation of the c-raf product at serine and threonine residues in intact cells. J. Biol. Chem. 266:7933-7939.

26. Ueki, K., S. Matsuda, K. Tobe, Y. Gotoh, H. Tamemoto, M. Yachi, Y. Akanuma, Y. Yazaki, E. Nishida, and T. Kadowaki. 1994. Feedback regulation of mitogen-activated protein kinase kinase kinase activity of c-Raf-1 insulin and phorbol ester stimulation. J. Biol. Chem. 269:15756-15761.

27. Kosako, H., E. Nishida, and Y. Gotoh. 1993. cDNA cloning of MAP kinase kinase reveals kinase cascade pathways in yeasts to vertebrates. EMBO (Eur. Mol. Biol. Org.) J. 12:787-794. 
28. Tobe, K., T. Kadowaki, H. Tamemoto, K. Ueki, K. Hara, O. Koshio, K. Momomura, Y. Gotoh, E. Nishida, Y. Akanuma, et al. 1991. Insulin and 12-O tetradecanoylphorbol-13-acetate activation of two immunologically distinct myelin basic protein/microtubule-associated protein 2 (MBP/MAP2) kinases via de novo phosphorylation of threonine and tyrosine residues. J. Biol. Chem. 266:24793-24803.

29. Tobe, K., T. Kadowaki, K. Hara, Y. Gotoh, H. Kosako, S. Matsuda, H. Tamemoto, K. Ueki, Y. Akanuma, E. Nishida, and Y. Yazaki. 1992. Sequential activation of MAP kinase activator, MAP kinases, and S6 peptide kinase in intact rat liver following insulin injection. J. Biol. Chem. 267:21089-21097.

30. Boulton, T. G., S. H. Nye, D. J. Robbins, N. Y. Ip, E. Radziejewska, S. D. Morgenbesser, R. A. DePinho, N. Panayotatos, M. H. Cobb, and G. D. Yancopoulos. 1991. ERKs: a family of protein-serine/threonine kinases that are activated and tyrosine phosphorylated in response to insulin and NGF. Cell. 65:663-675.

31. Sadoshima, J., Y. Xu, H. S. Slayter, and S. Izumo. 1993. Autocrine release of angiotensin II mediates stretch-induced hypertrophy of cardiac myocytes in vitro. Cell. 75:977-984.

32. Kojima, M., I. Shiojima, T. Yamazaki, I. Komuro, Y. Zou, Y. Wang, T. Mizuno, K. Ueki, K. Tobe, T. Kadowaki, et al. 1994. Angiotensin II receptor antagonist TCV-116 induces regression of hypertensive left ventricular hypertrophy in vivo and inhibits intracellular signaling pathway of stretch-mediated cardiomyocyte hypertrophy in vitro. Circulation. 89:2204-2211.

33. Komuro, I., Y. Shibazaki, M. Kurabayashi, F. Takaku, and Y. Yazaki. 1990. Molecular cloning of gene sequences from rat heart rapidly responsive to pressure overload. Circ. Res. 66:979-985.

34. Pelech, S. L., and J. S. Sanghera. 1992. MAP kinases: charting the regulatory pathways. Science (Wash. DC). 257:1355-1356.

35. Leberer, E., D. Dignard, D. Harcus, D. Y. Thomas, and M. Whiteway. 1992. The protein kinase homologue Ste20p is required to link the yeast pheromone response G-protein beta gamma subunits to downstream signalling components. EMBO (Eur. Mol. Biol. Org.) J. 11:4815-4824.

36. Sadoshima, J., and S. Izumo. 1993. Mechanical stretch rapidly activates multiple signal transduction pathways in cardiac myocytes: potential involvement of an autocrine/paracrine mechanism. EMBO (Eur. Mol. Biol. Org.) J. 12:16811692
37. Kolch, W., G. Heidecker, G. Kochs, R. Hummel, H. Vahidi, H. Mischak, G. Finkenzeller, D. Marme, and U. R. Rapp. 1993. Protein kinase C $\alpha$ activates RAF-1 by direct phosphorylation. Nature (Lond.). 364:249-252.

38. Lissoos, T. W., D. W. A. Beno, and B. H. Davis. 1993. 1, 25-dihydroxyvitamin D3 activates Raf kinase and Raf perinuclear translocation via a protein kinase C-dependent pathway. J. Biol. Chem. 268:25132-25138.

39. Zhang, X., J. Settleman, J. M. Kyriakis, E. Takeuchi-Suzuki, S. J. Elledge M. S. Marshall, J. T. Bruder, U. R. Rapp, and J. Avruch. 1993. Normal and oncogenic $\mathrm{p} 21^{\text {ras }}$ proteins bind to the amino-terminal regulatory domain of c-Raf1. Nature (Lond.). 364:308-313.

40. Thorburn, J., J. A. Frost, and A. Thorburn. 1994. Mitogen-activated protein kinases mediate changes in gene expression, but not cytoskeletal organization associated with cardiac muscle cell hypertrophy. J. Cell Biol. 126:1565-1572.

41. Thorburn, A., J. Thorburn, S.-Y. Chen, S. Powers, H. E. Shubeita, J. R. Feramisco, and K. R. Chien. 1993. HRas-dependent pathways can activate morphological and genetic markers of cardiac muscle cell hypertrophy. J. Biol. Chem. 268:2244-2249.

42. Baker, K. M., and J. F. Aceto. 1987. Angiotensin II stimulation of protein synthesis and cell growth in chick heart cells. Am. J. Physiol. 259:H610-618.

43. Katoh, Y., I. Komuro, Y. Shibazaki, H. Yamaguchi, and Y. Yazaki. 1989. Angiotensin II induces hypertrophy and oncogene expression in cultured cardiac myocytes. Circulation. 80(Suppl. II):II-450.

44. Dostal, D. E., and K. M. Baker. 1992. Angiotensin II stimulation of left ventricular hypertrophy in adult rat heart. Am. J. Hypertens. 5:276-280.

45. Brewster, J. L., T. de Valoir, N. D. Dwyer, E. Winter, and M. C. Gustin 1993. An osmosensing signal transduction pathway in yeast. Science (Wash. DC). 259:1760-1763.

46. Han, J., J.-D. Lee, L. Ribbs, and R. J. Ulevitch. 1994. A MAP kinase targeted by endotoxin and hyperosmolarity in mammalian cells. Science (Wash. DC). 265:808-811.

47. Galcheva-Gargova, Z., B. Derijard, I.-H. Wu, and R. J. Davis. 1994. An osmosensing signal transduction pathway in mammalian cells. Science (Wash. DC). 265:806-808.

48. Komuro, I., and Y. Yazaki. 1994. Intracellular signaling pathways in cardiac myocytes induced by mechanical stress. Trends Cardiovasc. Med. 4:117121. 